\title{
EM BUSCA DE DEFINIÇÕES
}

\author{
MAURÍCIO DE BONIS defende que a música erudita precisa \\ recuperar o potencial de comunicação que já teve
}

A concepção da arte como linguagem tem uma presença significativa em sua historiografia durante o século XX, em diversas correntes de interpretação. Em seu Philosophie der Kunstgeschichte, Arnold Hauser afirma que

\footnotetext{
"todo artista fala a linguagem de seus predecessores, e, de fato, passase longo tempo até que comece a falar com sua própria voz; não obstante, é uma simplificação excessiva afirmar que todo artista começa com a imitação de outro artista, e que toda obra de um primeiro período é cópia de uma obra mais antiga”.[1]
}

A critica à simplificação excessiva se dirige a Malraux, que em seu Voix $d u$ Silence declarara que "todo artista começa pelo pastiche. (...) A imitação apaixonada é uma operação banalmente mágica, e basta a um pintor lembrar-se de seus primeiros quadros, a um poeta seus primeiros poemas, para saber que ele encontra lá uma participação, não no mundo, mas no mundo da arte" [2]. Afirma que o primeiro Rembrandt não se dedica a representar a vida, mas a falar a língua de seu mestre Lastmann; "amar a pintura, para ele, é possuir, ao pintá-lo, o mundo pictural que o fascina” (idem). "É sobre esse pastiche que todo artista se conquista; o pintor passa de um mundo de formas a outro mundo de formas, $o$ escritor, de um mundo de palavras a outro mundo de palavras, da mesma forma que o músico passa da música à música", diz Malraux, apontando com clareza o caráter "não-imitativo" da música em relação à natureza ou à realidade sensível, em comparação com as outras artes. Não obstante, a distância dessa realidade na formação do artista é a mesma, independentemente do caráter mais ou menos marcadamente imitativo da arte em questão: “o mundo da arte não é um mundo idealizado, é um outro mundo; todo artista, para si mesmo, é semelhante 
ao músico" (idem). Expandindo a rede de relações para além do aprendizado direto (como no exemplo de Rembrandt), Malraux afirma que

\footnotetext{
“esse pastiche não é necessariamente aquele de um só mestre; ele une às vezes um professor a um ou mais mestres (...); ora mestres bastante diferentes entre si, ora mestres similares (...). Ocorre que um estilo é pastichado em seu conjunto; e mesmo menos que um estilo: um gosto de época, a ourivesaria do estilo florentino, a tapeçaria do veneziano, o expressionismo do último gótico alemão, a cor clara dos impressionistas, a geometria do cubismo".[3]
}

A idéia-chave de Malraux nessas páginas é a de que, se abordamos as artes em analogia com a linguagem - não importando a que elementos linguísticos, se comuns ou não a outras linguagens "não-artísticas", elas recorrem -, devemos abordá-las como linguagens autônomas, cada qual com sua própria história e seu modo de jogo particular; mais ainda, que a compreensão dessas linguagens e das intenções do artista passa pela relação direta com a história das obras (e principalmente com o contato com as obras imediatamente anteriores), mais do que pela natureza intrínseca dos objetos isolados que ele opera.

Hauser acrescenta, ao que ele considera uma simplificação por parte de Malraux, que é indiferente a relação entre Rembrandt e Lastmann ou entre El Greco e os venezianos: para ele o essencial seria observar que, independentemente da relação específica estabelecida por cada artista com seus predecessores, todos se expressam primeiramente na linguagem formal da velha geração; não há propriamente uma independência do passado, mas uma relação concreta com os meios de expressão existentes, ainda que para combatê-los (Hauser, op.cit.). Hauser relaciona as idéias de Malraux com as de Wölfflin antes dele, ou seja, de quanto uma pintura deve antes a outras pinturas do que à observação da natureza. Lembremos de uma formulação mais completa de Wölfflin:

\footnotetext{
"É leviandade imaginar que um artista tenha, alguma vez, podido colocar-se diante da natureza sem qualquer ideia preconcebida. Aquilo
} 
que ele adotou como conceito para a representação e o modo como esse conceito se desenvolveu, em seu íntimo, são fatores muito mais importantes do que tudo aquilo que ele extrai da contemplação direta (...). A observação da natureza é um conceito vazio, enquanto não soubermos sob quais formas ela é observada."[4]

Hauser argumenta que Malraux leva a um novo sentido a noção de Wölfflin, entendendo que a arte não é simplesmente "rival da natureza, mas a fonte em sentido próprio da inspiração artística e do conteúdo da obra a realizar”. A operação do artista, seja qual for sua relação com a natureza, reside no trabalho com a linguagem, materializada na história das obras - a ênfase do pensamento de Malraux estaria sempre na autonomia da arte, na "endogamia e autogênese das convenções artísticas". Hauser acrescenta ainda que, antes de Malraux e Wölfflin, o estudioso Konrad Fiedler já afirmava em 1914 que, quando o artista "tenta balbuciar, encontra de pronto um idioma em que pode expressarse”.[5]

Para Hauser a função da arte como linguagem encerra a solução para o problema de se "chegar a formulações comunicáveis de uma visão interior", mas contém um perigo (para o artista) na tensão dialética entre convenção e invenção, nos limites entre o questionamento das conformações linguísticas pré-existentes (e portanto padronizadas) e a manutenção do canal de comunicação, a preservação da linguagem de partida pura e simplesmente.[6]

René Huyghe contribui à mesma ordem de pensamento quando coloca que "o homem não vislumbra mais do que aquilo que já conhece, o que aprendeu a ver. (...) Da mesma maneira, o artista, por grande que seja, parte daquilo que já foi inventado antes dele", acrescentando que "é sempre fácil encontrar as 'fontes', isto é, as obras anteriores em que aprendeu o repertório de formas de que se servirá".[7] Mas ainda, para além do compartilhamento dessa visão com os autores que comentamos, Huyghe chega a uma distinção das relações entre arte e linguagem em tempos e sociedades distintas. Se o pintor, como o escultor, "precisa de uma linguagem", não obstante não se pode deixar de lado a oposição dialética entre o dado individual e o dado social em cada artista; “o 
artista de outrora era mais a expressão do grupo humano em que se integrava do que da sua personalidade, tornada o principal protagonista nos tempos modernos". [8] Para ele, uma das marcas da arte em tempos de tal exacerbação do individualismo é a da negação do passado, na reação contra a convenção linguística anterior.

\footnotetext{
“O 'ponto zero' está atingido, daqui por diante; o passado lentamente conquistado e adquirido encontra-se eliminado até nos seus menores traços. (...) Aqui estão estes homens, voluntariamente reduzidos ao seu ponto de partida. Reconstituem artificialmente uma situação quase análoga, não já à do homem primitivo (passamos muito além disso) mas à da Pré-História, em que colocado perante as forças ameaçadoras que ainda não sabia dominar, nem em si nem à sua volta, o nosso primeiro antepassado contatava com o enigma, então total, do mundo. E que encontrava? A angústia, a angústia de estar desarmado, superado, entregue ao incontrolável."[9]
}

Se há mais de cem anos a arte moderna se levanta contra as convenções estabelecidas porquanto elas não correspondem mais a uma nova visão de mundo e a uma nova ordem social, por outro lado a reação individualista a essas convenções traz o risco da redução da linguagem ao balbucio pré-linguístico primitivo, a uma tabula rasa que elimine a própria definição do campo de ação do artista, a uma anomia completa. Hauser ressalta o fenômeno dadaísta como um marco do início da "luta sistemática contra o uso dos meios convencionais de expressão e a consequente desintegração da tradição clássica oitocentista”. Abandonava-se a "renovação da própria linguagem", o "equilíbrio entre o velho e o novo, entre as formas tradicionais e a espontaneidade do indivíduo", substituindo-os por uma contradição: "como poderá alguém fazer-se entender - e é isso, em todo caso, o que o surrealismo pretende e, ao mesmo tempo, negar e destruir todos os meios de comunicação?". Para Hauser não é uma proposta como essa que caracterizaria em si a importância histórica do dadaísmo e do surrealismo, por exemplo, mas o fato de que esses movimentos "chamam a atenção para (...) a esterilidade de uma convenção (...) que já não tinha qualquer conexão com a vida real" [10]. 
Essa breve colagem de referências não deixa de apontar a influência da filosofia materialista (e mesmo de seu combate contra as tendências idealistas) no pensamento sobre a arte desde a segunda metade do século XIX. "Será necessária uma inteligência profunda para compreender que ao mudarem as relações de vida dos homens, as suas relações sociais, a sua existência social, mudam também suas representações, as suas concepções e os seus conceitos, numa palavra, a sua consciência?”, pergunta Marx, em linguagem simples e direta, no Manifesto comunista. "Que prova a história das ideias senão que a produção espiritual se transforma com a transformação da produção material?”[11]. Até René Huyghe, ao definir o postulado de seu Sentido e destino da arte, coloca com clareza essa herança (ainda que o próprio autor a negue):

\footnotetext{
“Todo este livro está baseado num postulado, cujo desenvolvimento e verificação ele perseguiu ao longo dos séculos, a saber, que o homem de um dado tempo e lugar projeta no seu sistema de ideias ou de imagens por meio das quais julga exprimir-se, na sua filosofia, literatura ou arte, o reflexo das mesmas preocupações: são, em linguagens diversas, as da sua época, tal como está modelada pelas circunstâncias materiais e morais, econômicas, sociais e espirituais. O gênio dos indivíduos não faz mais do que dar-lhes um significado mais universal e eterno pela amplidão e qualidade que chega a conferirlhes."[12]
}

Se a música em suas especificidades seja talvez um terreno ainda mais movediço para se assentar uma analogia com a noção de linguagem, é nesse mesmo combate a uma visão idealista (ainda em estreita relação com a "esterilidade das convenções” sobreviventes de que fala Hauser) que se assenta essa bibliografia. Em seu Le langage musical, Boucourechliev começa a definir o alcance dessa analogia argumentando que

\footnotetext{
“como a linguagem falada, a música é um sistema de diferenças (...), e que, como a linguagem falada, a música possui uma sintaxe, qualquer que seja a multiplicidade das sintaxes musicais das épocas sucessivas. No entanto, contrariamente à linguagem falada, a música não é firmemente presa a significados, nem diretos nem simbólicos”.[13]
} 
Para ele a ênfase sobre a sintaxe na abordagem linguística da música encerra um enfrentamento da permanência de uma visão romântica que se tornou anacrônica: "somos doentes de dois séculos de vã busca de um 'significado', de um sentido racional da música do qual a linguagem seria o 'portador'... Ora, em música, nada é portador de outra coisa”. Como na historiografia da arte que comentamos anteriormente, busca-se uma definição mais precisa e menos idealizada da relação entre convenção e invenção, entre o indivíduo e a sociedade, entre o papel do compositor e o do ouvinte nas operações linguísticas em música. “Terminada a obra, é portanto a estrutura a única realidade que se ergue diante de nós, com a qual nós podemos dialogar, que nós podemos interrogar e sobre a qual podemos dizer alguma coisa. E associar, livremente." Nesse espaço de associação subjetiva, por parte do ouvinte - e portanto já alheio à operação do compositor - residiria algo semelhante à "produção de sentido", na analogia proposta por Boucourechliev: "o sentido gravitaria 'em torno' da estrutura, como uma emanação dela. (...) É um modelo em todo caso mais aberto: ele deixa um espaço ao destinatário, à sua imaginação pessoal (e ao seu apetite): o sentido é você."[14]

Um aspecto sintomaticamente ausente do livro de Boucourechliev é a relevância das relações sociais na formação da linguagem musical - no decorrer do livro, as transformações históricas da linguagem parecem obras de indivíduos isolados. À parte uma breve referência à força da música como "sistema de ligação entre os homens", todo o seu trabalho se caracteriza por uma visão da música como linguagem apenas como estratégia material para o trabalho sobre a estrutura do discurso. Praticamente não há rastro da ligação inseparável entre a linguagem e a vida social (para além da intervenção individual do compositor), como aquela que se observa nos historiadores da arte comentados acima.

No comentário de Boucourechliev sobre a primazia da sintaxe no trabalho do compositor (sobrepondo-se à operação semântica), ele retoma uma máxima atribuída a Jakobson e retomada também por Nattiez: a de que "a música é uma linguagem que significa a si mesma" afirmação que tem sua origem no trabalho de um colega do compositor Henri Pousseur na Bélgica (como ele, aluno de André Souris e Pierre Froidebise), o linguista e musicólogo Nicolas Ruwet, em seu texto 
Contradictions du langage sériel[15]. Essa primeira reflexão de Ruwet sobre a linguagem tem um ponto de partida problemático, questionando a coerência do serialismo do ponto de vista da abordagem linguística da música, e na mesma publicação (um número extenso da Revue Belge de Musicologie, com o tema "música experimental") ele é acompanhado da resposta de Pousseur, no artigo Forme et pratique musicales.[16]

Ruwet começa acusando a música serial de uma contradição entre sua pretensa complexidade de concepção e sua simplicidade para o ouvinte, que recebe uma informação estática com uma completa "ausência de eventos, a não ser eventos muito elementares, primitivos". Como se se tratasse de uma música que "renunciasse a criar uma linguagem". Aponta que os serialistas "não têm uma consciência suficientemente clara do que significa o fato de que a música é linguagem", acusando-os de reduzir a linguagem apenas ao termo da parole em detrimento da langue (utilizando a divisão de Saussure), dedicando-se à operação sobre o material em detrimento da construção de um discurso do qual se percebessem e desenrolassem claramente suas relações no tempo. A abolição da operação concreta sobre a memória levara à abolição do próprio movimento, e portanto a uma música "monótona", "simplista". [17]

Se a crítica aos limites do serialismo tal como praticado na década de 1950 foi logo empreendida com propriedade pelo próprios compositores que o empregaram, o método de Ruwet é que se mostra inicialmente de uma simplicidade bastante insuficiente para fundamentar sua crítica. Sua argumentação é baseada na ineficiência das diferenciações extremamente precisas intentadas pelos compositores para o ouvinte, no que diz respeito à variação das durações e das intensidades, e em sua variação independente, um aspecto deveras localizado e elementar para ser significativo na compreensão do discurso ou da proposta serial como um todo. O próprio Nattiez aponta em Ruwet a falha de observar em suas análises o texto como objeto isolado dos problemas linguísticos mais gerais, do sistema de referência histórico, das características da obra do compositor estudado, do gênero no qual a obra se insere[18].

A resposta de Pousseur extrapola os pontos levantados por Ruwet para 
se desenhar como uma visão ampla dos problemas enfrentados pela música na época por um compositor com uma aguda consciência histórica da linguagem. "Não é possível explicitar o sentido, a origem, a vida de uma forma (...) sem se referir às relações sociais a que essa forma remete, sem evocar as relações que ela estabelece com os indivíduos participantes da prática musical onde ela se realiza"[19]. O ponto de partida de Pousseur já naquela época (ainda muito próximo da experiência serial) é claríssimo na consciência histórica da linguagem musical tal como ela se articulava em tempos de prática comum: trata-se de estudar "o que é comum às obras de uma época, o reservatório das fórmulas correntes. Com isso, tendemos a definir a ideia central, o étimo coletivo que polarizou a economia ideológica e linguística desta época, sem talvez se realizar de uma maneira absoluta em nenhuma obra em particular”.[20] Exemplificando suas premissas a partir do sistema tonal, Pousseur insiste que as relações harmônicas existem apenas em um contexto social bem definido; é pela ação do homem, em sua relação dialética com o contexto social, que se produzem as bases da transformação da percepção auditiva. Para Pousseur, assim como para o compositor brasileiro Willy Corrêa de Oliveira, cujos textos comentaremos em seguida, é uma constante a definição da ação do compositor não apenas pela sua força de invenção, mas vendo-o como um ser social. "Os homens fazem sua própria história, mas não a fazem como querem; não a fazem sob circunstâncias de sua escolha e sim sob aquelas com que se defrontam diretamente, legadas e transmitidas pelo passado".[21]

Rastros do pensamento marxista pairam, em vagas analogias, nos textos de vários compositores contemporâneos - como na referência frequente de Boulez à "revolução permanente". Mas, se para alguns a referência é pouco mais que superficial, se alguns encerrariam a referência na frase seguinte a essa citação d'O 18 Brumário de Luís Bonaparte ("a tradição de todas as gerações mortas oprime como um pesadelo o cérebro dos vivos"), outros se baseiam de maneira mais sólida sobre esse pensamento, em que se vislumbra que a “opressão" da tradição precisa ser superada - ideia expressa por Marx, inclusive, em uma analogia com a linguagem: 


\begin{abstract}
"O principiante que aprende um novo idioma traduz sempre as palavras deste idioma para sua língua natal; mas, só quando puder manejá-lo sem apelar para o passado e esquecer sua própria língua no emprego da nova, terá assimilado o espírito desta última e poderá produzir livremente nela." [22]
\end{abstract}

Tratava-se, no contexto das discussões sobre a linguagem musical na segunda metade do século XX, da formação de um "novo idioma"; a grande ilusão, da qual muitos não se afastaram, é a da possibilidade da criação artificiosa de uma língua (que se pretenda coletiva, universalizante) pelo engenho individual, como aponta Willy Corrêa de Oliveira nos textos que comentamos mais adiante.

Nesse aspecto, Pousseur se mostra um utópico incorrigível; para ele, se a linguagem musical chega a uma situação crítica no século XX por sua relação inseparável com a vida social, a ação do homem no sentido inverso poderia engendrar uma reação a essa situação. Essa ação, ainda que operada apenas no âmbito da estrutura musical, carregaria a mensagem de uma outra visão de mundo possível - e, portanto, confirmaria a pertinência de um projeto de linguagem que se pretendesse coletivo, ou até universal, mesmo que nascido da imaginação individual. Retornaremos a esse tema ao tratar dos textos de Willy Corrêa de Oliveira, de suas aproximações e afastamentos do pensamento de Pousseur. De qualquer forma, para esses dois pensadores a obra de Marx permanece um dos fundamentos para a reflexão sobre a linguagem musical. Retornando ao ensaio de Pousseur, seu comentário sobre a música tonal registra a presença da ideia de Marx sobre a passagem histórica da burguesia do papel de revolucionária para o de reacionária com a conquista do domínio político.[23]

\footnotetext{
"Em linhas gerais, pode-se dizer que a formação da linguagem tonal foi um dos ramos da elaboração do individualismo burguês.

Revolucionária a princípio, por oposição à estrutura hierática e teocrática da sociedade feudal (que possuía, ela também, suas formas de expressão e de prática musical próprias), dividida pela Reforma e domesticada pela Contra-Reforma, ela finda por se tornar (corroída então aquela busca da liberdade pessoal por uma sede de autoridade individual) um sistema petrificado, gerador de alienação, e que os
} 


\begin{tabular}{|c|c|c|c|}
\hline celeuma & número 4 | maio 2014 & dossiê & 75 \\
\hline
\end{tabular}

espíritos mais lúcidos desejam ultrapassar."[24]

Pousseur nota que, no campo musical, essa reação à ordem anterior que faz corpo com a reação a uma ordem social estabelecida só poderia se articular, naquele momento, sob a forma do individualismo; o passar do tempo revelaria, com o início do século XX, o quanto o individualismo exacerbado tornaria a operação com a linguagem necessariamente hermética, culminando na ausência de uma linguagem comum.

Na sequência de seu ensaio Pousseur responde mais diretamente a Ruwet, reconhecendo a princípio que o primeiro período do serialismo integral, associado ao pensamento pontilhístico ("ponctuelle"), sofria realmente de uma certa indiferenciação - e ressaltando que os próprios compositores seriais foram os primeiros a afirmá-lo. A reação teórica e empírica a essa limitação levou ao que Pousseur entende como um segundo período da música serial, com a substituição da noção central "pontual" por aquela de "grupo", que recuperaria a possibilidade clara de diferenciação e de construção de "estruturas mais vastas”. Demonstra que os exemplos musicais específicos citados na crítica de Ruwet já continham exemplos de composição com grupos e com fortes diferenciações, incompreendidas pelo linguista.

Pousseur segue ainda questionando com propriedade a argumentação linguística de Ruwet, no que seu ensaio extrapola a relação com este trabalho. Pousseur relembra esse ensaio mais de dez anos depois, acrescentando o quanto essas questões foram pouco desenvolvidas (por ainda não lhe serem tão claras em 1959) e desenvolvendo adiante sua concepção da linguagem musical (e do sentido da abordagem linguística da música) no prefácio (“contendo uma resposta a Lévi-Strauss”) do livro Fragments théoriques I sur la musique expérimentale (1970).

A resposta a Lévi-Strauss consiste no significativo posicionamento de Pousseur contra a tese do antropólogo na introdução de $O$ cru e o cozido, em particular ao ataque ao serialismo como sistema arbitrário, sem relação orgânica com o material que ele utiliza. Pousseur atribui parcialmente a uma imprudência excessiva nas afirmações de Boulez o ponto de partida do ataque de Lévi-Strauss à arbitrariedade serial. $\mathrm{O}$ 
próprio Pousseur já havia demonstrado em diversos textos (aos quais ele se refere nesse prefácio) que, "longe de negar as propriedades 'naturais' da matéria sonora e musical, Webern aplicava-se ao contrário a operálas de uma maneira nova"[25]. Sua argumentação segue apontando uma fraca compreensão por parte de Lévi-Strauss da origem natural dos intervalos e de suas funções na história da linguagem musical e ainda acusando o embasamento do autor d'O cru e o cozido sobre uma separação demasiadamente mecânica entre as noções de natureza e cultura. Essas mesmas contestações da crítica de Lévi-Strauss estão presentes em um texto de Willy Corrêa de Oliveira publicado originalmente em 1977 e incluído em seu livro Beethoven, proprietário de um cérebro[26], em que ele empreende ainda uma análise linguística do sistema tonal ("executada a quatro mãos com o prof. José Miguel Wisnik"). Essa argumentação seria posteriormente expandida incluindo uma comparação com uma análise linguística da música serial - em seus cursos ministrados na Universidade de São Paulo.[27]

Pousseur enuncia naquele mesmo prefácio que "entre tradição - viva - e experimentação - realista - não há ruptura de continuidade”. Em segundo lugar, "do fato precisamente da grande ausência de um sistema coletivo ao qual os compositores modernos pudessem se referir (...), é bem evidente que esses compositores têm de 'experimentar' de uma maneira muito mais geral e mais permanente que seus antecessores"[28]. Em seu texto Epígrafe e alguns apontamentos sobre a linguagem (incluído em sua tese de doutoramento, Cadernos), Willy começa com uma citação de Jacques Bouveresse, evocando Wittgenstein: "aquele que crê que é possível inventar pura e simplesmente uma outra linguagem esquece que 'imaginar uma linguagem quer dizer imaginar uma forma de vida' (Investigações filosóficas \$19) e que uma forma de vida, rigorosamente, não se 'inventa"'[29]. À epígrafe segue a abertura do ensaio de Willy:

\footnotetext{
"O mundo capitalista contemporâneo - do ponto de vista da música erudita - não possui língua falada.

Isso deveria ser um absurdo, posto que equivale a dizer que

determinada comunidade não tem língua comum: em resumo, não se comunica. Ou mesmo aventurar-se a crer que certa comunidade, não tendo língua falada, se expressasse através de língua morta. (...) Aquilo
} 


\begin{tabular}{l|ll}
\hline celeuma & número 4 | maio 2014 & dossiê \\
\hline
\end{tabular}

que afeta ser a fala de uma língua morta não passa da imitação dessa

língua, (...) a defunta linguagem da música erudita, no mundo

capitalista, não serve para a comunicação. Ostenta-se, em casos

escassos, como objeto vagamente identificável."[30]

Essa linha de pensamento não se dá no abandono da atividade criativa, como poderia se supor à primeira leitura - muito pelo contrário, 0 catálogo de Willy mostra uma produção muito mais intensa nos últimos vinte anos do que na década de 1970. Ela caracteriza uma produção intensa em direção distinta daquela que o norteara décadas antes, com um afastamento marcante da esperança linguística construtiva que Pousseur mostra em seus textos, por exemplo (ainda que a insistência de Pousseur nesse projeto utópico o tenha levado à amargura de seus últimos depoimentos e entrevistas).

A visão materialista sobre a linguagem musical que havia caracterizado a produção teórica de Willy e Pousseur nas décadas de 1960 e 1970, num embate por um caminho construtivo, por uma solução mais orgânica para a composição da música de seu tempo, é complementada nessa reavaliação (30 anos depois) pelo desvelamento de uma incompatibilidade de base, de um terreno social, econômico e cultural verdadeiramente infértil para a inserção da produção que eles intentavam. Da operação com os rastros de linguagem (ou com novos arremedos de linguagem, individualmente engendrados) restam expressões individuais que não alcançam a possibilidade de um compartilhamento verdadeiro, de um vislumbre das intenções e implicações na relação entre a construção e a percepção do discurso, quer o compositor busque essa comunicação ou não. Em uma das cartas ficcionais de seu ensaio Retrato do artista quando só, um dos personagens - um crítico - escreve que os compositores contemporâneos não vivem dos proventos de suas composições contemporâneas. Geralmente, como outros elementos da classe média, eles são executivos, professores, engenheiros, médicos... que compõem. Cada um pode inventar sua própria língua, língua desconhecida, porque no fundo ele não fala com ninguém[31].

É exatamente contra essa ordem de atuação, a da aceitação pura e 
simples de uma solução individual para uma expressão individual, que se situavam as críticas de Pousseur em uma mesa-redonda com Berio e Boulez em 1963; em sintonia com a necessidade da recuperação de uma relação orgânica com a história que desse à música erudita atual a possibilidade de almejar à função social e à dimensão comunicativa (em toda sua especificidade, bem entendido) que ela chegou a possuir em sua história. Pousseur dizia que "não é possível falar sem se referir à totalidade da cultura que o carrega ou que o precede"[32]. Em Epígrafe e alguns apontamentos sobre a linguagem, Willy desenvolve:

\footnotetext{
“A primeira língua de um homem não se exaure no aprendizado de um vocabulário: é uma forma de conhecimento, de catecismo social; não se aprende só os nomes das coisas, mas a unidade das coisas e seus nomes, mais ainda as origens de quem diz e aponta para as coisas. Aprender a falar a primeira língua é principiar a entrar no mundo, a comungar com o princípio do mundo, a descobri-lo, e não uma decoração de um léxico para as coisas do mundo, e para tudo o que ocorre. (...) O aprendizado da primeira língua é, portanto, uma forma de conhecimento, e não uma forma de tradução. Tanto que o pensamento do homem recende à sua língua mãe, se ressente de seu sotaque."[33]
}

Mais do que nunca, "não é possível falar sem se referir à totalidade da cultura que o carrega ou que o precede"; a enunciação dessa frase em 1963 por Pousseur já mostra a consciência de uma falácia generalizada no que eles acreditavam que seria uma nova prática comum a partir do legado de Webern e da experiência serial de modo geral. Se a comunicação na linguagem musical ocorrera, nos sistemas de referência do passado, com a especificidade de uma linguagem em que a semântica se assenta sobre a sintaxe, não é no simples engendrar de uma nova sintaxe a partir de experiências isoladas que se recupera a comunicabilidade em larga escala. Essa nova sintaxe se ressente de uma prática desaparecida para sua efetividade plena. É na consciência desse estado de coisas que Willy e Pousseur vislumbram em seus processos criativos o aprendizado da língua morta como substituto da comunhão em uma língua-mãe. 
Pousseur e Willy haviam respondido com veemência ao ataque de LéviStrauss à música serial (como já comentamos acima), ressaltando entre outros argumentos a solidez de seu embasamento sobre dados materiais, "naturais", do fenômeno sonoro. O aprofundamento da discussão leva a um questionamento mais concreto não da experiência serial em si, mas da situação em que a criação musical se debate desde a desintegração da herança tonal e da prática social que a acompanhava: a dialética entre natureza e cultura, cuja necessidade primordial ambos advogam na constituição de um sistema de referência coerente na linguagem musical, não pode ser devidamente articulada (ao menos não com o mesmo fim, com a mesma efetividade) se se entende como dado cultural a ação individual pura e simples. Raymond Court, outro participante da discussão com Lévi-Strauss na época, ao comentar o conjunto vasto das possibilidades fonéticas da laringe humana, coloca que quando a criança "sai da fase do "balbucio"” opera-se uma redução da gama de possibilidades fonéticas, como a "contrapartida exata das possibilidades infinitas de expressão que permite a posse de uma língua situada culturalmente e fundada sobre um sistema específico de fonemas"[34]. A infinita riqueza e variedade do material sonoro na música contemporânea não seguiria a lógica inversa, em analogia ao balbucio primevo na ausência de língua falada? A vasta riqueza material da música contemporânea não deixava de denunciar a Pousseur, ao mesmo tempo, sua "secura expressiva", que o levara a buscar com sua música um "enriquecimento semântico" perdido[35]. No campo de ação que lhes resta, Willy e Pousseur recusam o "balbucio" e sua riqueza sonora de superfície, para recuperar uma comunicabilidade ainda possível nos rastros remanescentes da linguagem. Não pretendem falar em uma língua morta, mas engendrar em suas experiências individuais discursos que recuperem o potencial de comunicação que a linguagem musical possuiu no passado. Não para repetir a música do passado, mas para que seja possível exprimir, ainda, ideias musicais no presente.

Também em seus Cadernos, no Caderno do Princípio e do Fim, que foi publicado em parte como artigo (excluindo o terço inicial, introdutório) [36], dialoga com os apontamentos do Caderno de Pânico em uma sequência de argumentações. Documenta a presença pífia da música erudita no mercado fonográfico (avaliada, na época, pela sua presença 
estatística na prensagem de CDs), incluindo nessa pequena produção todo o repertório histórico, e ainda gêneros paralelos incluídos na mesma classificação. Incompatibilidade entre a linguagem e o modo de produção:

\footnotetext{
"O pouco de música erudita que se transformou em mercadoria faz exigências muito elevadas. (...) Para o consumo de música do passado, o ouvinte carece de preparação histórica e técnica que o habilite a decodificar aquilo que ele escuta. Há que situar a obra em seu contexto sociocultural; compreender o sistema de referência (de cuja organização do material musical a obra é expressão); as interrelações de ordem morfológica; ter o conhecimento e a frequentação das obras que possibilite ao ouvinte a distinção idioletal; e consciência (no plano mesmo da composição) dos parâmetros do som e suas potencialidades linguísticas. De outro modo, aquilo que ele ouve é apenas uma manifestação acústica, sem muito mais. Como trovão ou abalroamento de automóveis."[37]
}

Um extenso trabalho de pesquisa seria necessário para verificar o quanto a educação musical e a formação musical avançada proporcionam sequer aos músicos uma tal relação consciente com o repertório (ainda que nos restringíssemos apenas ao repertório do passado), para que sua relação com seu próprio trabalho ultrapasse a sua intuição, sua subjetividade (ou a imitação pura e simples do trabalho alheio). Que dizer então do potencial de comunicação da música erudita (como expressão que se assenta sobre a operação sintática) na sociedade atual? A consciência histórica de seu estado atual passa pela avaliação de uma época inteira (que já dura mais de século) na qual, em contraste com as funções sociais que ela exerceu no passado (cuja dinâmica cambiante fazia corpo com as transformações na própria linguagem), a crise na comunicação coloca em xeque sua própria existência como linguagem.

Se as "exigências muito elevadas" para a comunicação em música erudita dificultam sua veiculação como mercadoria, o problema é ainda mais grave quando se discute não a qualidade (ou a estratégia) do ensino da linguagem, visando ou não a formação específica, mas o acesso a ele pura e simplesmente: "o poder aquisitivo e custo de manutenção do educando, 
a disponibilidade de tempo de dedicação aos estudos, possibilidades de frequentação das obras musicais, abrangência das relações interdisciplinares, exequibilidade dos materiais didáticos necessários” [38]. Isso considerando-se a dedicação semanal por anos seguidos.

Como já comentamos, o resultado dessa dificuldade não é precisamente o de uma elitização da prática musical, e sim de sua descaracterização como linguagem, de sua incompreensão generalizada, a ponto de não se estranhar a anomia a que se pode chegar no assim chamado mercado da música hoje, na falta de uma clareza mínima na distinção entre os gêneros, entre as diferentes linguagens musicais, entre as atividades elementares da prática musical. Nesse meio crítico para a música erudita de maneira geral, a parcela mais minoritária, mais marginalmente atendida é a da criação, no que diz respeito às possibilidades para a composição e a circulação da música contemporânea - o que por si só já consiste em um sintoma dos mais agudos para a crise da linguagem, como situação oposta àquela que predomina por toda a história da música, em que a circulação via de regra é da música recém-criada. As relações de trabalho no capitalismo tornam predominante a condição surgida ainda no século XIX, o pré-requisito do tempo livre, do ócio, para a possibilidade da criação. Isolamento que sobreproblematiza a já difícil comunicabilidade da música atual, pela profusão das linguagens possíveis, como soluções individualizadas na ausência de linguagem comum. “Tão díspares, opostas, várias, inviáveis quantas. Algo próximo da ideia de uma Babel construída no pátio de uma casa de orates”.[39]

[1] Hauser, Arnold. Introducción a la historia del arte. Madrid: Guadarrama, 1961, p.479.

[2] Malraux, André. Les voix du silence. Paris: Gallerie de la Pléiade, 1951, p. 310. [3] Idem, p.312-313. "Ce pastiche n'est pas nécessairement celui d'un seul maître; il unit parfois un professeur à un ou à des maîtres (...); parfois entre eux des maîtres assez différents, parfois des maîtres apparentés (...). Il advient qu'un style soit pastiché dans son ensemble; et même moins qu'un style: un goût d'époque, l'orfèvrerie du style florentin, la tapisserie du vénitien, l'expressionisme du gothique allemand finissant, la couleur claire des impressionnistes, la géométrie du cubisme". [4] Wölfflin, Heinrich. Conceitos fundamentais da história da arte. Trad. João Azenha Jr. São Paulo: Martins, 2001, p.319-320

[5] Hauser, op.cit., p.479-481.

[6] Idem, p.481-482.

[7] Huyghe, René. Sentido e destino da arte. Lisboa: Edições 70, 1986, vol.1, p.27.

[8] Idem, p.26. 
[9] Huyghe, René. Sentido e destino da arte. Lisboa: Edições 70, 1986, vol.2, p.274. [10] Hauser, Arnold. História social da arte e da literatura. São Paulo: Martins Fontes, 1998, p.962-964.

[11] Marx, Karl; Engels, Friedrich. Manifesto do partido comunista. Moscou: Progresso, 1987, p.52.

[12] Huyghe, op.cit., p.253.

[13] Boucourechliev, André. Le langage musical. Paris: Fayard, 1993, p.9.“(...) comme le langage parlé, la musique est un système de différences (...) et que comme la langage parlé, la musique possède une syntaxe, quelle que soit, la multiplicité des syntaxes musicales des époques successives. Cependant, contrairement au langage parlé, la musique n'est pas rivée à des significations, ni directes ni symboliques".

[14] Idem, p.11-14.

[15] Posteriormente incluído na sua coletânea Langage, musique, poésie (1972).

[16] Pousseur, Henri. Écrits théoriques 1954-1967. Sprimont: Mardaga, 2004, p.261-278.

[17] Ruwet, Nicolas. "Contradictions du langage sériel”. Revue belge de musicologie, v.13, n.1/4, 1959, p.83-88.

[18] Nattiez, Jean-Jacques. “Langage, musique, poésie by Nicolas Ruwet”. Anuário Interamericano de Investigación Musical, v.9. Texas University Press, 1973, p.187.

[19] Pousseur, op.cit., p.261.

[20] Pousseur, op.cit., p.262.

[21] Marx, Karl. O 18 Brumário de Luis Bonaparte. São Paulo: Escriba, 1978, p.329.

[22] Idem.

[23] Marx, Karl; Engels, Friedrich. Manifesto do partido comunista. Moscou: Progresso, 1987, p.36-40.

[24] Pousseur,op.cit., p.263. "En gros, l'on peut dire que la formation du langage tonal fut l'une des branches de l'élaboration de l'individualisme bourgeois.

Révolutionnaire d'abord, par opposition à la structure hiératique et théocratique de la société féodale (qui possédait, elle aussi, ses formes d'expression et de pratique musicale propres), divisé par la Réforme et domestiqué par la Contre-Réforme, il finit par devenir lui-même (rongée qu'est alors cette quête de la liberté personnelle par une soif de l'autorité individuelle) un système figé, générateur d'aliénation, et que les esprits les plus lucides souhaitent dépasser".

[25] Pousseur, Henri. Fragments théoriques I sur la musique expérimentale. Bruxelles: Université libre de Bruxelles, 1970, p.16.

[26] Oliveira, Willy Corrêa de. Beethoven: proprietário de um cérebro. São Paulo: Perspectiva, 1979, p.139-145.

[27] Ulbanere, Alexandre. Willy Corrêa de Oliveira: por um ouvir materialista histórico. São Paulo: dissertação de mestrado, Instituto de Artes da UNESP, 2005, Anexos, p.116-120.

[28] Pousseur, op.cit., p.14-15.

[29] Oliveira, Willy Corrêa de. "Caderno de Pânico". In: Cadernos. Tese de Doutorado em Artes, Escola de Comunicações e Artes da USP, 1998, p.42.

[30] Idem.

[31] Idem, p.39.

[32] Nattiez, Jean-Jacques. “Table ronde de 1963, journées des 16, 18 et 23 juillet". Circuit: musiques contemporaines. Montréal: Université de Montréal, v. 15, n.3, 2005, p.39.

[33] Oliveira, op.cit., p.45-46.

[34] Court, Raymond. "Langage verbal et langages esthétiques".Musique en jeu, Paris: Seuil, no. 2, jan-mar. 1971, p.17.

[35] Pousseur, op.cit., p.289.

[36] Oliveira, Willy Corrêa de. "Como 'Cem homens e uma garota”. Revista de história. São Paulo: DH/FFLCH/USP, n. 157, dez. 2007, p.73-99.

[37] Oliveira, Willy Corrêa de. "Caderno do Princípio e do Fim”. In: Cadernos. 


\begin{tabular}{l|l|l|l|l|}
\hline celeuna & número 4 maio 2014 \\
\hline
\end{tabular}

Tese de Doutorado em Artes, Escola de Comunicações e Artes da USP, 1998, p.23.

[38] Idem, p.25.

[39] Idem, p.27.

MAURícIO DE BONIS é compositor e professor do Instituto de Artes da Unesp. 